\title{
CLOSING THE LOOP BETWEEN PROJECT NETWORK SIMULATION RESEARCH AND PEDAGOGY
}

\author{
John E. Taylor \\ Columbia University \\ 618 S.W. Mudd Building \\ 500 West 120th Street \\ New York, NY 10027 USA
}

\begin{abstract}
The introduction of simulation into pedagogy has been demonstrated by researchers to enhance learning outcomes. However, the use of simulation in classroom environments can provide an opportunity to pretest simulation research designs and to identify new potential avenues of theoretical inquiry that can be explored through simulation research. This paper presents the results of five years of experience integrating simulation research on project networks into project management courses. Initial attempts to integrate research-oriented computational simulation models met with limited success. An intermediary set of inclass exercises and a simplified web-based version of the project network simulation were created to expose students to the impact of network structure on adaptation performance. This strengthened comprehension by the students. However, it also led to an iterative expansion of the research from a narrow focus on network relational stability to include designs focused on cultural and linguistic differences, retention loss and opportunistic behavior.
\end{abstract}

\section{INTRODUCTION}

Researchers have shown that the use of in-class simulations (Smith and Boyer 1996) and computational simulations (Jong and Joolingen 1998, Mayer 2003, Hmelo-Silver 2003) used in pedagogical settings generate a more active learning environment. Researchers have concluded that computer simulations, when coupled with lectures, generate higher order thinking that enables students to apply learning across a range of scenarios (Gokhale 1996, Jong 2006, Veenmam et al. 1994). Some researchers claim that some in-class practice-based simulations can be efficiently replaced by computational simulation (Dewhurst et al. 1994); however, research has shown that integrating the two leads to the most learning and retention (Jong et al. 1995).

This paper presents the results of a five year effort to integrate simulation research on project network dynamics into project management courses. Early efforts to expose undergraduate and graduate students to research-oriented computational simulation models met with limited success. The research version of the project network dynamics was coded in Python, was developed with a non-graphical user interface, and required exporting comma separated value (csv) files and manipulation in another software environment to analyze the results. As a result the pedagogical objective of exposing students to the impact of various strategies on the performance of firms and firm networks was obfuscated by the difficulties of learning new software and analytical procedures.

This paper is organized as follows. In the following section the subject matter of the simulationproject network dynamics-will be summarized. The next section presents a chronological series of efforts to make the simulation and the pedagogical objectives associated with the simulation more understandable to undergraduate and graduate students. The paper will conclude with a discussion of the impli- 


\section{Taylor}

cations of the key learning points from these efforts. A key learning and the primary impetus behind developing this manuscript is the fact that the iterative process exposed an important feedback look. In addition to being a beta-testing environment for simulation research, the pedagogical efforts emerged as a rich source of new research conjectures, research designs and ultimately new experiments.

\section{PROJECT NETWORK DYNAMICS}

Projects in the architecture, engineering and construction (A/E/C) industry are complex, interdisciplinary endeavors requiring the task interdependent efforts of multiple distinct specialist organizations to be completed. As the complexity of the projects increases, the collaborative work processes at the intersection between activities and organizations becomes increasingly important. This increases the importance of the knowledge of how specialist organizations work together to complete interdependent tasks. And yet, in the highly fragmented United States $\mathrm{A} / \mathrm{E} / \mathrm{C}$ industry, projects are often temporary networks of firms that disband after the project and are reformed with a different group of collaborating firms on the next project. This means that the collaborative knowledge on how to effectively complete a complex, interdependent task may not carry forward to the next project.

Early work on $\mathrm{A} / \mathrm{E} / \mathrm{C}$ project networks emphasized the relational stability of project networks even to the extent that the network of firms was referred to as a quasi-firm (Eccles 1981). However, today A/E/C project networks are referred to as temporary organizations, or coalitions (Pryke 2004). Project network dynamics investigates how this shifting participation from one project to the next (what we term relational instability), coupled with the organizational boundary spanning task interdependent nature of the work, impacts the efficient implementation and diffusion of innovations and organizational changes (Taylor and Levitt 2007). Simulation research on the impact of project network structure on change dynamics revealed that relational instability coupled with task interdependence between organizations working on a project can lead to protracted learning curves following the introduction of innovations or organizational changes that span organizational boundaries in the network (Taylor, Levitt and Villarroel 2009).

\section{INTEGRATING PROJECT NETWORK DYNAMICS SIMULATION INTO PEDAGOGY}

\subsection{First Attempt to Integrate Python-based Version of Project Network Dynamics Simulation}

In 2006, an attempt was made to expose undergraduate and graduate students in a project management course to the Python-based version of the project network dynamics simulation mentioned earlier. The students were frustrated by the requirement to utilize a software and coding language unfamiliar to them while at the same time having to complete the multiple file conversion steps required to generate the performance curves that resulted from varying strategic approaches employed. At the same time, the Project Network Dynamics Lab was being launched. In order to attract research students into the lab it was decided that a more accessible introduction into project network dynamics was needed.

\subsection{Combining In-class Pedagogical Simulation with Python-based Version of the Simulation}

In 2007, the key attributes of the simulation were abstracted and developed into an in-class simulation exercise. In the classroom simulation, students were broken into project networks. Each network was comprised of architects, engineers and contractors and each network was asked to complete five successive projects. Each project involved designing, specifying and building a small model of a building. Each role had specific instructions to follow and each project could only be completed with the interdependent collaborative efforts of all three participant types.

At the start of each project the architect was given an envelope with a rough set of design requirements and a sheet of graph paper. The design indicated specific aspects of the design, e.g., how many interior walls, how many windows or doors and the locations of the windows or doors. Once plan and elevation drawings were completed by the architect, the graph paper was passed to an engineer who was 


\section{Taylor}

provided with a building code that indicated the material type requirements for internal walls, external walls and foundations, as well as the room dimension requirements. From this information the engineer added to the drawings the material types and dimensions of the structure. Finally, the graph paper was passed to the contractor who was tasked with building the building according to the design and specifications. Once complete an inspection was completed and any rework completed before the time to complete the first project was recorded. This continued until five distinct projects were complete.

As this effort to work together to design, specify and construct a small building was new to the participants, the improvements over each successive project were assumed to approximate the adaptation to an innovation or organizational change impacting the industry. To achieve project network relational instability we gave half of the groups a six-sided die with a 1,2 or 3 in equal distribution indicated on the faces of the die. At the end of each project the team rolled the die to determine which of three architects, the three engineers and the three contractors would participate in the project. This added a stochastic element to the determination of which specialists would participate in each project. For the remaining half of the groups there was no stochastic element. These groups were comprised of only one architect, one engineer and one contractor. For these groups the learning from working together on one project ported to the next project interaction. At the end of the exercise we averaged the performance of the relationally stable groups and the performance of the relationally unstable groups and compared the performance over time.

This more hands-on approach to understanding the impact of relational instability on project network change performance improved the students' initial grasp of the concept in the undergraduate and graduate project management courses. However, the second step of the assignment was to utilize the Python-based version of the simulation to examine various contracting strategies. The underlying concept was conveyed in a more accessible pedagogical fashion; however, the crucial aspect of the pedagogical effort-to examine various contracting approaches in situations of varying relational instability and task interdependence-was still encumbered by the unfamiliar software and multiple file conversion steps required to complete the exercise.

\subsection{Combining In-class Pedagogical Simulation with Web-based Version of the Simulation}

In 2008, the pedagogical approach to teaching project network dynamics was enhanced one step further. We isolated the key attributes of the Python-based research version of the simulation and developed a web-based version of the project network dynamics simulation to accompany the in-class simulation described above. A screenshot of the web-based version of the tool is contained in Figure 1 and Figure 2. With the web-based version of the tool, the students could interact with a single application within any web browser to examine the productivity impact on individual firms and the project network over time. In Figure 1 the network is relationally stable (only one architect, one engineer and one contractor) with no task interdependence (directional task interdependence is added by increasing the percentage on the arrows connecting the specialists). In this case the productivity of each firm (graphed in the bottom right graph in Figure 1) and the network (graphed in the bottom left graph in Figure 1) are equivalent over the 25 projects simulated. In this relationally stable, task independent network, the network and each associated firm achieve the pre-innovation performance (indicated as a red dashed line) after only 3 projects.

In Figure 2 a relationally unstable ( 3 architects, 4 engineers and 5 contractors) and task interdependent (values vary depending on specific interaction) project network is simulated in the web-based version of the simulation. Here the students observe that the network will not consistently outperform its pre-innovation productivity until the $18^{\text {th }}$ project. Yet the students may also observe that some firms in the bottom right graph achieve their pre-innovation productivity by the $9^{\text {th }}$ project while some others still have not achieved their pre-innovation performance by the $25^{\text {th }}$ project. Hence the students are able to extend the micro-level observations of their group's performance in the classroom simulation to examine a wide variety of scenarios in the web-based version of the simulation. This coupling of in-class and (accessible) computational simulation led to strong learning outcomes. In fact, with the improved outcomes new simulation experimental designs began to emerge. 


\section{Taylor}

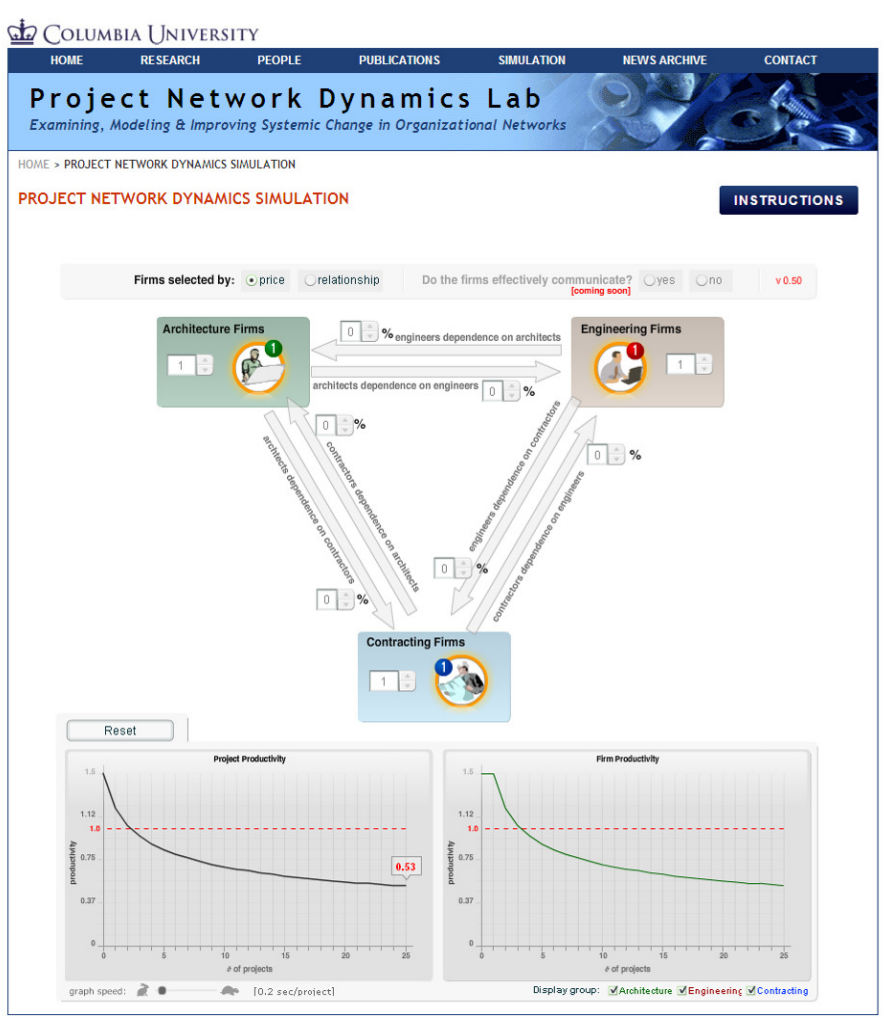

Figure 1: Web-based Simulation of Relationally Stable, Task Independent Network

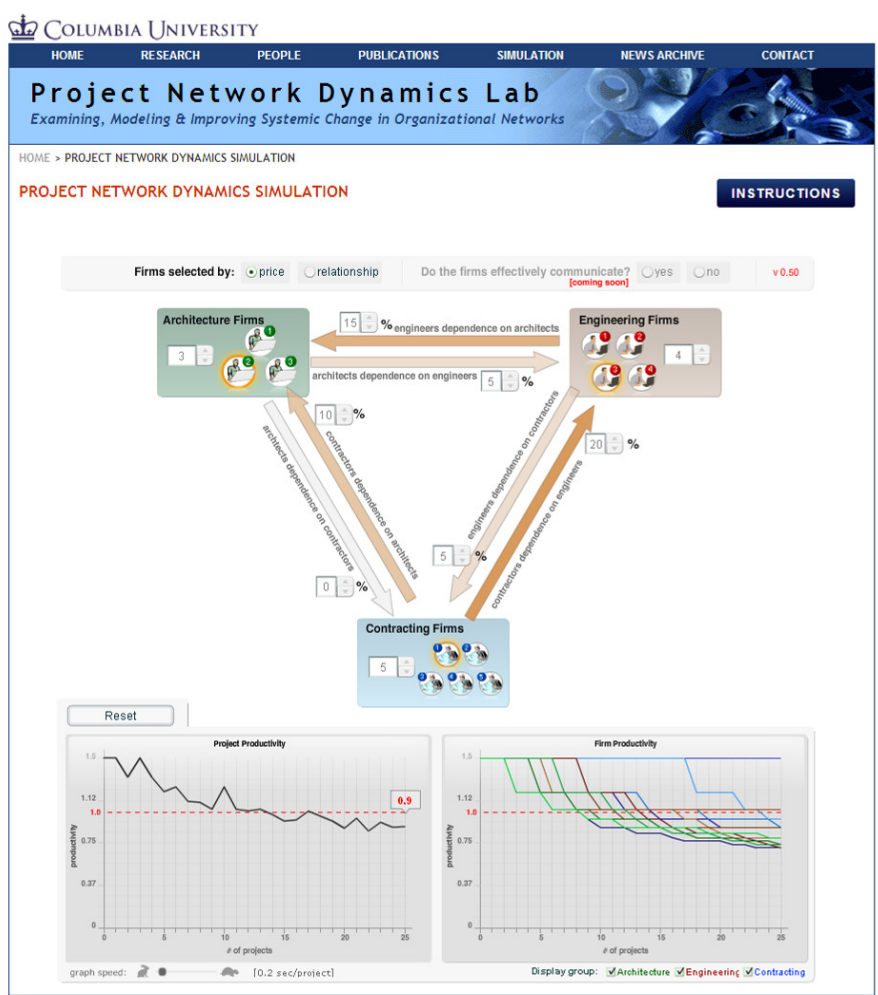

Figure 2: Web-based Simulation of Relationally Unstable, Task Interdependent Network 


\section{Taylor}

\subsection{Synergistic Feedback Loop from Pedagogical Integration of Simulation Research}

By 2009 we had collected a large number of project network adaptation performance curves from the undergraduate and graduate courses in which we ran the simulations. Several key variables emerged from the performance curves and discussions with the students about those curves in post-simulation debrief sessions which we then pursued in simulation research in 2009 and 2010.

The first variable was related to communication. The courses contained a large number of international students and in some cases differences in adaptation performance appeared to correlate with potential cultural and linguistic differences in the team. We searched the literature for empirical data we could emulate in the simulation to model cultural and linguistic differences in global project networks. Finding none, we refined the in-class pedagogical simulation for the purposes of research data collection and designed an experiment with 30 domestic participants and 30 international participants. This led to statistically distinct performance and an interesting theoretical contribution. The culturally and linguistically diverse teams took about 50\% longer to complete the first project. However, they had better adaptation performance and were able to outperform the domestic team by the fourth project. This contribution may resolve a tension in the cross-cultural interaction literature in which some find cross-cultural differences have a positive impact on performance and still others find a negative impact. This research suggests that both may be correct depending on whether they are referring to initial performance, adaptation performance, or performance after several opportunities to interact.

The second variable that emerged from discussions with the students was the impact of long spans of time that may separate two dyad specific interactions in relationally unstable networks. The students wondered if performance would decay over the gap in time. To explore this we studied existing empirical models of retention loss and integrated the leading empirical model into the project network dynamics simulation to accommodate the expected loss in performance gains that unfold during gaps of time between interactions. From a modeling perspective this was a challenge as we were required to link an event-based learning model with a time-based retention loss decay model.

The third variable that emerged from interactions with the students was a confounding mechanism. A student asked why - if tight partnerships would lead to improved learning outcomes-we did not observe more relationally stable contracting behavior in industry. This led to an extension of the research version of the simulation to integrate game theoretic modeling to examine the impact of opportunistic behavior. Economists describe the opportunistic behavior a buyer may exert over a seller of as the hold-up problem. We were able to demonstrate with the game theory integrated project network dynamics simulation that a hold-up problem can occur in project networks where members of the project network attempt to accrue more than their share of the economic rents associated with improvements in performance following the introduction of an innovation or organizational change. We then created a web-based version of the game theory integrated project network dynamics simulation and used it to empirically validate the theoretical proposition that emerged from the simulation effort.

\section{IMPLICATIONS AND CONCLUSIONS}

This paper describes efforts to integrate simulation research on project network dynamics into project management pedagogy at the undergraduate and graduate level. Research has demonstrated that integrating in-class simulation with computational simulation can improve learning outcomes. The efforts presented in this paper are in line with this finding, however, in the case of the project network dynamics simulation the computational simulation to which the students were exposed needed to be integrated into a single, commonly used application and the range of parameters adjustable in the simulation simplified. The main purpose of this paper, however, is to point out the synergies that can result when simulation research is effectively integrated into pedagogy. Once we were able to clearly articulate and allow the students to experience project network dynamics through in-class simulation and a simplified web-based 


\section{Taylor}

computational version of the research simulation, a feedback loop emerged in which the simulation research agenda was being advanced through the engagement with the students. Empirical models for retention loss were emulated and integrated into the project network dynamics simulation. More importantly, fundamental theories of cross-cultural interaction and hold-up were extended as a result of the student feedback loop which resulted in new simulation experiments. By investing the time to create an in-class simulation exercise and simplified web-based version of the simulation we were able to synergistically close the loop between project network simulation research and pedagogy.

\section{ACKNOWLEDGMENTS}

This material is based upon work supported by the National Science Foundation under Grant No. 0729253. Any opinions, findings, and conclusions or recommendations expressed in this material are those of the authors and do not necessarily reflect the views of the National Science Foundation. The author would like to also thank the many undergraduate and graduate researchers who have participated in the project network dynamics simulation and pedagogical integration over the past five years.

\section{REFERENCES}

Dewhurst, D., J. Hardcastle, P. Hardcastle, and E. Stuart. 1994. Comparison of a computer simulation program and a traditional laboratory practical class for teaching the principles of intestinal absorption. Advances in Physiology Education 12(1): 95-104.

Eccles, R. 1981. The quasifirm in the construction industry. Journal of Economic Behavior and Organization 2(4): 335-357.

Gokhale, A. 1996. Effectiveness of Computer Simulation for Enhancing Higher Order Thinking. Journal of Industrial Teacher Education 33(4): 36-46.

Hmelo-Silver, C. 2003. Analyzing collaborative knowledge construction: multiple methods for integrated understanding. Computers \& Education 41: 397-420.

Jong, T., 2006. Technological Advances in Inquiry Learning. Science 312(5773): 532-533.

Jong, T., and W. Joolingen. 1998. Scientific Discovery Learning with Computer Simulations of Conceptual Domains. Review of Educational Research 68(2): 179-201.

Jong,T., E. Martin, J. Zamarro, F. Esquembre, J. Swaak, and W. Joolingen. 1995. The Integration of Computer Simulation and Learning Support: An Example from the Physics Domain of Collisions. Journal of Researching Science Teaching 36(5): 597-615.

Mayer R. 2003. The promise of multimedia learning: using the same instructional design methods across different media. Learning and Instruction 13: 125-139.

Pryke, S. 2004. Analysing Construction Project Coalitions: Exploring the Application of Social Network Analysis. Construction Management and Economics 22(8): 787-797.

Smith, E., and M. Boyer. 1996. Designing In-Class Simulations. Political Science and Politics 29(4): 690-694.

Taylor, J., and R. Levitt. 2007. Innovation Alignment and Project Network Dynamics: An Integrative Model for Change. Project Management Journal 38(3): 22-35.

Taylor, J., R. Levitt, and A. Villarroel. 2009. Simulating Learning Dynamics in Project Networks. Journal of Construction Engineering and Management 135(10): 1009-1015.

Veenman, M., J. Elshout, and V. Busato. 1994. Metacognitive Mediation in Learning With ComputerBased Simulation. Computers in Human Behavior 10: 93-106.

\section{AUTHOR BIOGRAPHY}

JOHN TAYLOR is an Assistant Professor of Construction Engineering and Project Management within the Department of Civil Engineering and Engineering Mechanics at Columbia University. He received 


\section{Taylor}

his Ph.D. from Stanford University in 2006. He is Director of the Project Network Dynamics Lab at Columbia University and his research interests include project organizational network dynamics associated with cross-boundary information system integration, inter-cultural interactions on global projects, and the diffusion of energy efficient practices in building occupant networks. He is an Associate Editor of the Journal of Computing in Civil Engineering, the Organizational Issues Specialty Area Editor for the Journal of Construction Engineering and Management, and a Corresponding Member of the Editorial Board for the Journal of Management in Engineering. His email is <jt2411 @ columbia.edu>. 